\title{
Thirty distinct CACNA1F mutations in 33 families with incomplete type of XLCSNB and Cacna1f expression profiling in mouse retina
}

\author{
Krisztina Wutz ${ }^{1}$, Christian Sauer ${ }^{2}$, Eberhart Zrenner ${ }^{3}$, Birgit Lorenz ${ }^{4}$, Tiina Alitalo ${ }^{5}$, \\ Martina Broghammer ${ }^{6}$, Martin Hergersberg ${ }^{7}$, Albert de La Chapelle, \\ Bernhard HF Weber ${ }^{2}$, Bernd Wissinger ${ }^{6}$, Alfons Meindl ${ }^{*, 1}$ and Carsten M Pusch ${ }^{6,8}$
}

\begin{abstract}
${ }^{1}$ Abteilung Medizinische Genetik der LMU, München, Germany; ${ }^{2}$ Institut für Humangenetik, Biozentrum, Würzburg, Germany; ${ }^{3}$ Abteilung für Pathophysiologie des Sehens und Neuro-Ophthalmologie, Universitätsaugenklinik, Tübingen, Germany; ${ }^{4}$ Abteilung für Kinderophthalmologie, Strabismologie und Ophthalmogenetik, Klinikum der Universität, Regensburg, Germany; ${ }^{5}$ Helsinki University Hospital, Helsinki, Finland; ${ }^{6}$ Molekulargenetisches Labor der Universitätsaugenklinik, Tübingen, Germany; ${ }^{7}$ Medizinische Genetik der Universität, Zürich, Switzerland; ${ }^{8}$ Institut für Anthropologie und Humangenetik, Tübingen, Germany
\end{abstract}

X-linked CSNB patients may exhibit myopia, nystagmus, strabismus and ERG abnormalities of the Schubert-Bornschein type. We recently identified the retina-specific L-type calcium channel $\alpha 1$ subunit gene $C A C N A 1 F$ localised to the $\mathrm{Xp11.23}$ region, which is mutated in families showing the incomplete type (CSNB2). Here, we report comprehensive mutation analyses in the 48 CACNA1F exons in 36 families, most of them from Germany. All families were initially diagnosed as having the incomplete type of CSNB, except for two which have been designated as Åland Island eye disease (ÅIED)-like. Out of 33 families, a total of 30 different mutations were identified, of which 24 appear to be unique for the German population. The mutations, 20 of which are published here for the first time, were found to be equally distributed over the entire gene sequence. No mutation could be found in a classic ÅlED family previously shown to map to the CSNB2 interval. Cacna1f expression in photoreceptor-negative mice strains indicate that the gene is expressed in the outer nuclear, the inner nuclear, and the ganglion cell layer. Such a distribution points to the central role of calcium regulation in the interaction of retinal cells that mediate signal transmission. European Journal of Human Genetics (2002) 10, 449-456. doi:10.1038/sj.ejhg.5200828

Keywords: ophthalmogenetics; mutation screening; CSNB2

\section{Introduction}

X-linked congenital stationary night blindness (XLCSNB; OMIM 310500) is a non-progressive eye disorder exhibiting life-long night vision impairment and variably reduced day vision. Patients with XLCSNB may also suffer from myopia, hyperopia, nystagmus and strabismus. In XLCSNB, the electroretinogram (ERG) is of the Schubert-Bornschein type

\footnotetext{
${ }^{*}$ Correspondence: A Meindl, Department of Medical Genetics at the Ludwig-Maximilians-University, Goethestr. 29, 80336 Munich, Germany. Tel: ++49-89-5160-4467; Fax: ++49-89-5160-4780;

E-mail: alfons@pedgen.med.uni-muenchen.de

Received 13 December 2001; revised 24 April 2002; accepted 25 Apri 2002
}

thereby allowing for a differentiation into two subtypes, namely the incomplete (ie CSNB2) and the complete phenotype (ie CSNB1). ${ }^{1,2}$ While in CSNB1 patients no postreceptoral rod-mediated function is measurable with ERG, some activity is retained in the incomplete subtype. In contrast, cone function is more impaired in patients with the incomplete type, as can be seen in scotopic 30 Hertz flicker responses and dark adaptation tests. ${ }^{3-6}$

We and others have recently isolated the genes mutated in $\mathrm{CSNB}^{7,8}$ and CSNB2 families. ${ }^{9,10}$ The CACNA1F gene, mutated in CSNB2 families, comprises 48 exons and codes for a protein which consists of 1966 amino acids showing high homology 
to $\alpha 1$-subunits of L-type calcium channels. Its expression is restricted to the retina and initial mutation analyses revealed loss of function as well as missense mutations. ${ }^{9}$

So far, mutation spectra have been published only for mixed populations ${ }^{10,11}$ or few Japanese families. ${ }^{12}$ In order to establish a mutation spectrum for the German population and to further support the strong association of the CACNA1F gene with CSNB2, we completed analysis in 10 families partially characterised previously ${ }^{9}$ and included another 24 CSNB2 families to the study. Additionally, we analysed the entire coding region of CACNA1F in two patients published with an AIED-related phenotype, and in the classic AIED family. ${ }^{13,14}$ To further understand the molecular pathogenesis of the mutated CACNA1F gene, we initiated a refined analysis of the gene expression in two mouse models displaying photoreceptor degeneration.

\section{Results}

The majority of CSNB2 patients harbour mutations in the CACNA1F gene

We have recruited 33 non-related XLCSNB families and one sporadic case, diagnosed with the incomplete type of CSNB, based on ERG data and dark adaptation tests. Recently, we published 10 of these families showing mutations in the CACNA1F gene by analysing 38 of the 48 exons. ${ }^{9}$ After completion of the mutation analyses, we identified a recurrent stop mutation (R82X) and a novel missense mutation (L849P) in families R3 and R6 respectively, in addition to a previously identified missense mutation R508Q. Including the newly recruited families, we have identified one insertion mutation, three deletion mutations, eight nonsense mutations, five alterations affecting conserved residues of splice sites, and 13 distinct missense mutations (Table 1).

In family $\mathrm{T} 9$ with four affected males we identified a missense mutation (R1171P) and a stop mutation (R1816X) in CACNA1F. Recently we also found a predicted missense mutation (V36F) in the RPGR gene ${ }^{15}$ in this family. The V36F alteration was found to segregate within the family and was not present in 600 controls. ${ }^{16}$ All three variants were found in the four affected males but not in controls (Figure 1). A novel missense mutation (C1488R) was identified in family R11 with four males suffering from incomplete CSNB. Sequencing revealed a change at nucleotide position 4462, causing a non-conservative amino acid exchange from cysteine to arginine at amino acid position 1488. The substituted cysteine residue is located in the

Table 1

\begin{tabular}{|c|c|c|c|c|}
\hline Family & Base change & Amino acid change & Exon & Type \\
\hline F40 & 151del5bp & & 2 & frameshift \\
\hline S41 & $220 \mathrm{~T} \rightarrow \mathrm{C}$ & Cys 74 Arg & 2 & missense \\
\hline R3 & $244 \mathrm{C} \rightarrow \mathrm{T}$ & Arg 82 ter $^{b}$ & 2 & stop \\
\hline $\mathrm{R} 4$ & $244 \mathrm{C} \rightarrow \mathrm{T}$ & Arg 82 ter $^{b}$ & 2 & stop \\
\hline T15 & $685 \mathrm{~T} \rightarrow \mathrm{C}$ & Ser 229 Pro & 6 & missense \\
\hline T22 & $781 G \rightarrow A$ & Gly 261 Arg & 6 & missense \\
\hline $\mathrm{R} 2^{\mathrm{a}}$ & $1106 \mathrm{G} \rightarrow \mathrm{A}$ & Gly 369 Asp & 8 & missense \\
\hline T7 & $1282 \mathrm{C} \rightarrow \mathrm{T}$ & Gln 428 ter & 10 & stop \\
\hline T2 & $1840 \mathrm{C} \rightarrow \mathrm{T}$ & Arg 614 ter & 14 & stop \\
\hline B27 & $2225 \mathrm{~T} \rightarrow \mathrm{G}$ & Phe 742 Cys & 17 & missense \\
\hline T24 & 2387-1 $(\mathrm{G} \rightarrow \mathrm{C})$ & & 20 & splice \\
\hline R6 & $2546 \mathrm{~T} \rightarrow \mathrm{C}$ & Leu 849 Pro & 21 & missense \\
\hline T10 & $2673+3(G \rightarrow A)$ & & 21 & splice \\
\hline T26 & $2673+3(G \rightarrow A)$ & & 21 & splice \\
\hline T17 & $2674-2,3$ (delCA) & & 22 & splice \\
\hline $\mathrm{R} 14^{\mathrm{a}}$ & $2872 \mathrm{C} \rightarrow \mathrm{T}$ & Arg 958 tre & 24 & stop \\
\hline $\mathrm{R} 26$ & $3019 G \rightarrow A$ & Gly 1007 Arg & 25 & missense \\
\hline $\mathrm{R} 13^{\mathrm{a}}$ & $3145 \mathrm{C} \rightarrow \mathrm{T}$ & Arg 1049 Trp & 27 & missense \\
\hline T13 & $3203 \mathrm{~T} \rightarrow \mathrm{C}$ & Leu 1068 Pro & 27 & missense \\
\hline $\mathrm{R} 22^{\mathrm{a}}$ & 3133 ins $^{b}$ & & 27 & frameshift \\
\hline R5 & 3658del12 bp & & 30 & in fame deletion \\
\hline $\mathrm{R} 25$ & $3862 \mathrm{C} \rightarrow \mathrm{T}$ & Arg 1288 ter $^{b}$ & 33 & stop \\
\hline $\mathrm{T} 12$ & $3942+2(T \rightarrow C)$ & & 33 & splice \\
\hline T6 & $3942+2(T \rightarrow A)$ & & 33 & splice \\
\hline $\mathrm{R} 21^{\mathrm{a}}$ & $4042 \mathrm{C} \rightarrow \mathrm{T}$ & Gln 1348 ter & 35 & stop \\
\hline $\mathrm{R} 15^{\mathrm{a}}$ & $4091 \mathrm{~T} \rightarrow \mathrm{A}$ & Leu 1364 His & 35 & missense \\
\hline $\mathrm{H} 15$ & $4101-1(G \rightarrow C)$ & & 36 & splice \\
\hline R11 & $4462 \mathrm{~T} \rightarrow \mathrm{C}$ & Cys 1488 Arg & 38 & missense \\
\hline R29 & $4466 C \rightarrow G$ & Pro 1489 Arg & 38 & missense \\
\hline R7 & $4466 C \rightarrow G$ & Pro 1489 Arg & 38 & missense \\
\hline R23 & $4490 \mathrm{~T} \rightarrow \mathrm{C}$ & Leu 1497 Pro & 39 & missense \\
\hline $\mathrm{R} 10^{\mathrm{a}}$ & $4771 \mathrm{~A} \rightarrow \mathrm{T}$ & Lys 1591 ter & 41 & stop \\
\hline T9 & $5446 \mathrm{C} \rightarrow \mathrm{T}$ & Arg 1816 ter & 46 & stop \\
\hline
\end{tabular}

${ }^{\mathrm{a}}$ Families reported previously (Strom et $a l^{9}$ ); ${ }^{\mathrm{b}}$ other known mutations. 


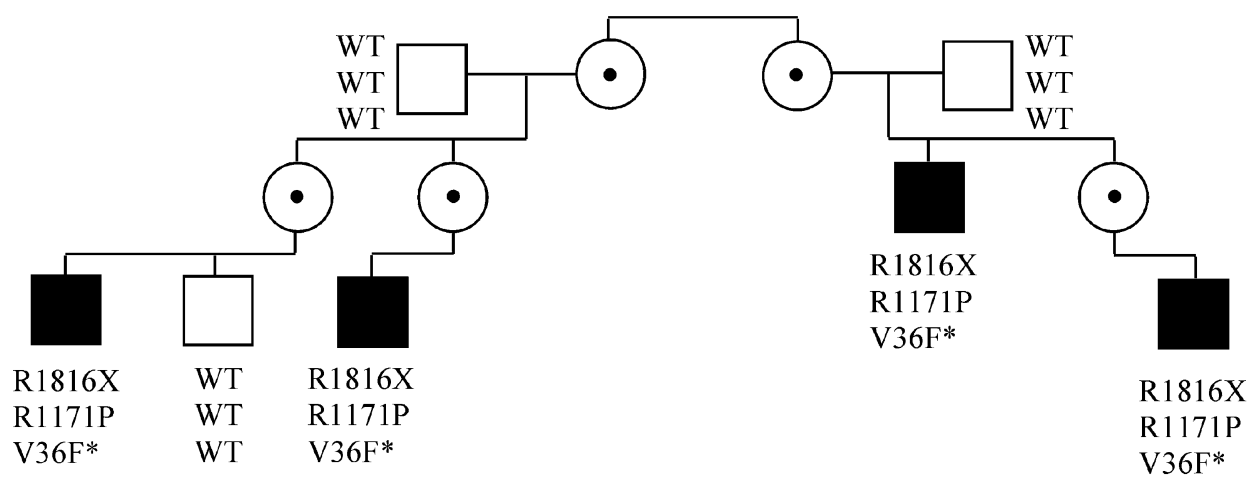

Figure 1 Mutation analysis in CSNB2 family T9. Pedigree of the family with affected males indicated by black boxes and obligate carrier females by a circle with a black dot. All patients and female heterozygotes are carrying both a stop (R1816X) and a missense mutation $(\mathrm{R} 1171 \mathrm{P})$ in CACNA1F, together with a missense mutation $\left(\mathrm{V}^{2} 6 \mathrm{~F}^{*}\right)$ in RPGR. These variants were not present in controls (WT).
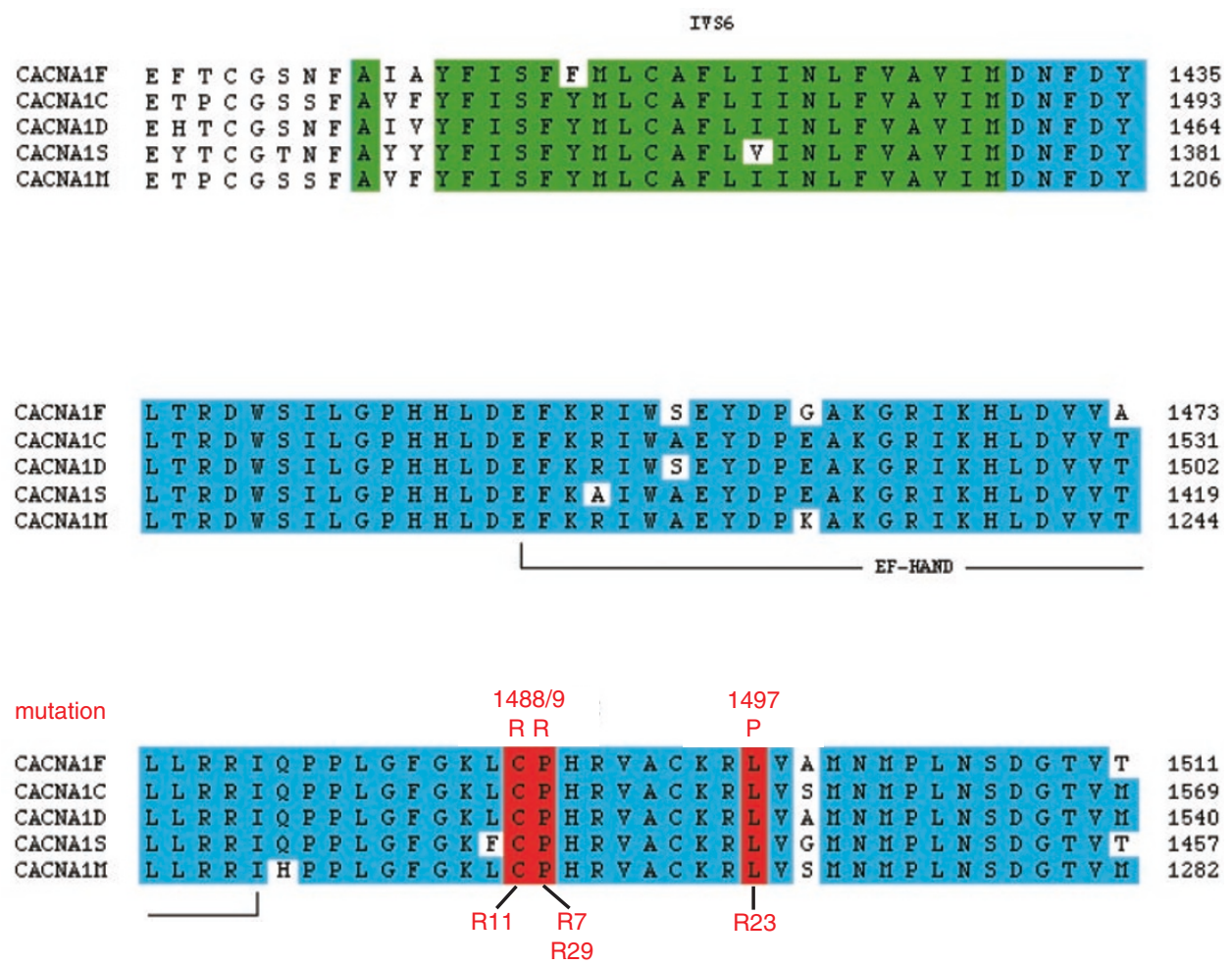

Figure 2 Partial alignment of the CACNA1F protein with other human L-type calcium channels. The figure shows the alignment from the respective transmembrane domains IVS6 (green) and the carboxyterminal cytoplasmic domain (blue). Non-shaded alignment positions indicate amino acids that are divergent from the overall CACNA1 consensus of the illustrated region. Conserved positions where three different missense mutations reside (in family R11 with C1488R, families R29 and R7 with P1489R, and family R23 with L1497P) are highlighted by red-shaded boxes. The putatively affected EF-hand motif is put into brackets.

cytoplasmic domain of the protein, similar to the two other novel missense mutations P1489R and L1497P (Table 1). These mutations may alter the calcium ion-binding site which is formed by the adjacent EF hand motif ${ }^{17}$ (Figure 2 ), although consequences for the interaction with other proteins cannot be excluded.
Other non-conservative amino acid changes were found at position 229 in family T15, at position 261 in family T22 (both exon 6), and at amino acid position 1068 (family T13). Mutations S229P and G261R reside in the aminoterminal and carboxy-terminal intracellular loop, respectively, located between transmembrane segments IS5 and 
IS6. Mutation 3203T $>\mathrm{C}$ in family $\mathrm{T} 13$ results in a nonconservative leucine to proline change at peptide position 1068. This region belongs to a highly conserved domain in the center of the intracellular loop connecting CACNA1F transmembrane segments IIIS5 and IIIS6 that both carry dihydropyridine interaction residues. Remarkable conservation can be observed between the related L-type calcium channels CACNA1D, CACNA1C and CACNA1S in the region from amino acid position 1058-1085. None of these missense mutations segregating in the corresponding families were found in 120 controls, and with the exception of L849P, affect amino acid residues which are highly conserved between the human and mouse $\alpha 1$-subunits of L-type calcium channels. ${ }^{9}$

In addition, we detected six distinct splice site mutations in seven unrelated families (Table 1). In all cases, the consensus splice donor or acceptor sites were affected and the variant was segregating with the disease. As the gene is not expressed in leukocytes, the expected consequences on the RNA splicing behaviour could not be determined.

A mutation in the CACNA1F gene was also found in a Finnish family (F40) with a phenotype diagnosed as being ÅIED-like. ${ }^{18}$ The PCR product, which generated an SSCP mobility shift which segregated in the family (Figure 3a), was sequenced and revealed a $5 \mathrm{bp}$ deletion in exon 2 of the gene (Figure $3 b$ ), predicting a truncation of the protein 65 amino acid residues downstream, resulting in a newly created stop codon TGA at nucleotide position 350. In addition, a missense mutation was found in a single sporadic case (S41) diagnosed with an ÅIED-related phenotype based on a hypopigmented fundus, pale optic discs, strabismus and congenital nystagmus. The T-to- $\mathrm{C}$ transition at nucleotide position 220, causing C74R, was not identified in 120 control chromosomes; however, the mutation occurred in the patient's mother. Notably, the affected cysteine residue is located in the highly conserved amino-terminal intracellular loop.

No mutations were found in families T19 and T20 as well as an isolated CSNB2 case (data not shown). These patients were also analysed by complete sequencing of $C A C N A 1 F$.

\section{Mutation screening in the original Åland Island eye disease family}

Åland Island eye disease has been mapped to the pericentromeric region of the $\mathrm{X}$ chromosome overlapping the region for CSNB2. ${ }^{14,19}$ Several ophthalmological findings in this family such as negative scotopic and abnormal photopic waveforms of the electroretinogram, and the defective dark adaptometry ${ }^{20}$ suggested allelic heterogeneity to incomplete XLCSNB. ${ }^{14}$ Analysis of all 48 exons of the CACNA1F gene by complete DNA sequencing revealed no aberration in an affected male. ${ }^{14}$ However, intronic mutations causing eg exon skipping cannot be assessed as retinal tissue was not available from affected individuals.
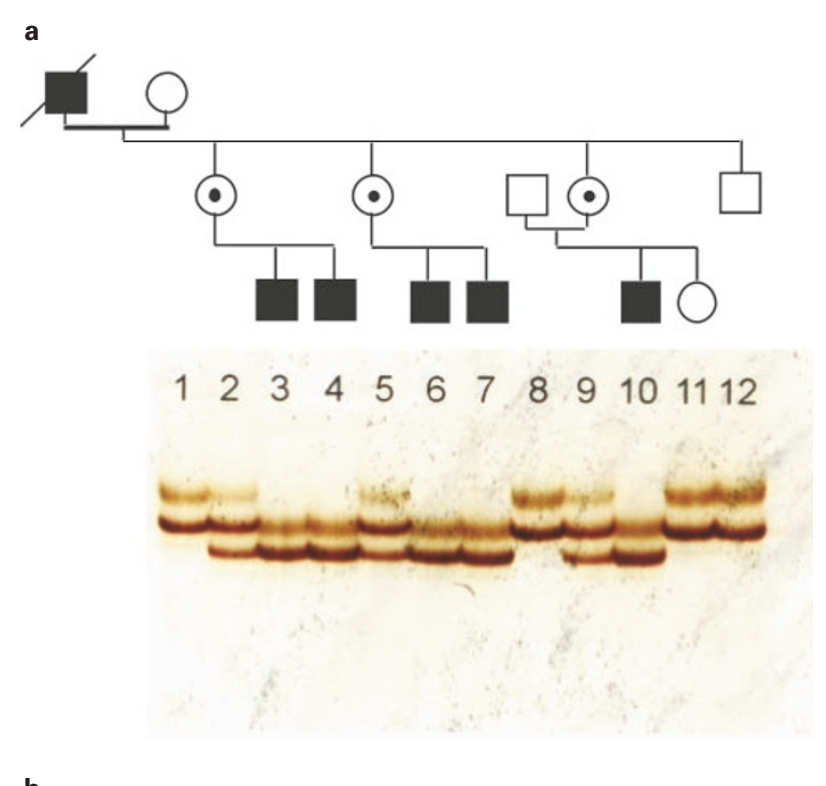

b

del 5 bp

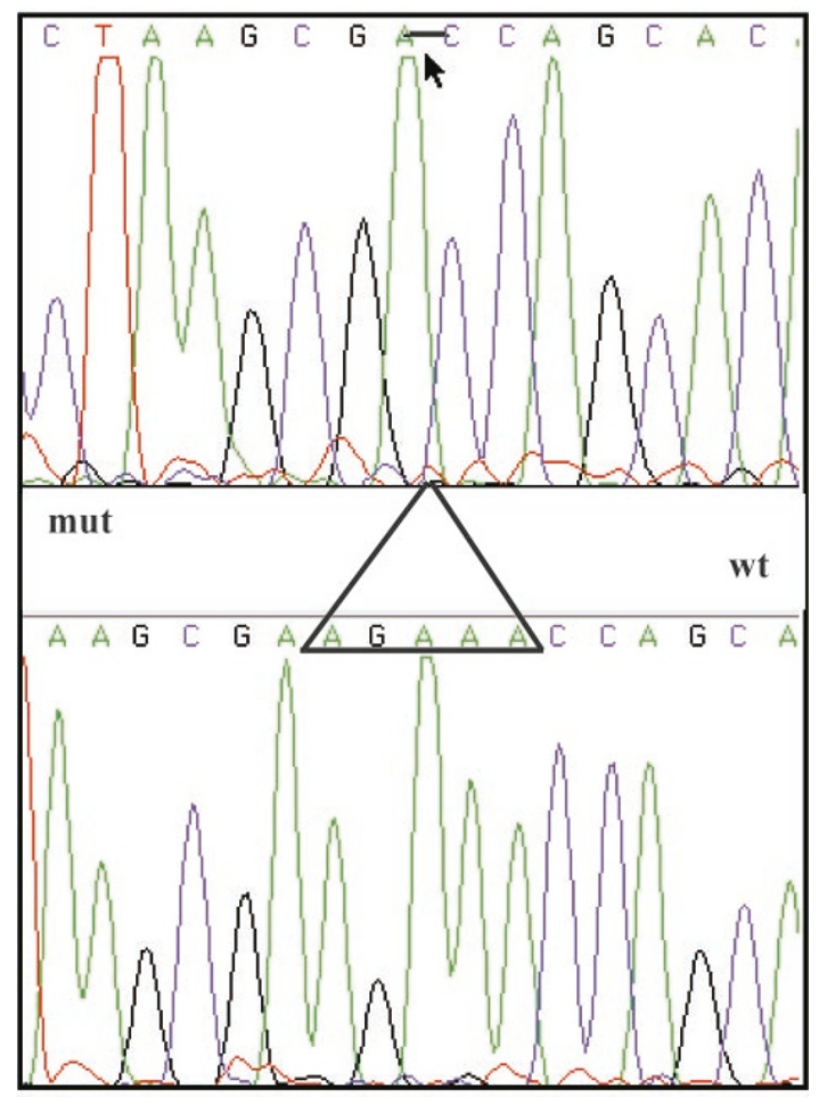

Figure 3 Family F40 from Southern Finland with an ÅIED-like phenotype. ${ }^{18}$ (a) Results of the CACNA1F exon 2 SSCP analysis (bottom panel) are shown in relation to the pedigree members (top panel). (b) Mutation analysis via direct sequencing of PCR products reveals a 5 -bp deletion ( $\triangle$-AGAAA) in exon 2 of $C A C$ $N A 1 F$ (top panel). For comparison, the bottom panel displays the wild type sequence of an unaffected proband. 
Expression of the $C A C N A 1 F$ gene is not restricted to photoreceptor cells

Initial RNA in situ hybridisation experiments using mouse eye sections were done with a human CACNA1F probe. ${ }^{9}$ The data showed that transcriptional activity is primarily present within the photoreceptor cells as well as in other retinal cell types originating from the inner nuclear and the ganglion cell layer. We have now repeated the in situ hybridisation experiments with a riboprobe encoding the orthologous gene in mice, termed Cacna1f. This has confirmed expression in the outer part of the nuclear layer, the inner part of the inner nuclear layer, and the ganglion cell layer as well (data not shown).

To further refine the expression analysis of the Cacna1f gene, we performed RT - PCR experiments in mouse strains with photoreceptor degeneration. In particular, we used the mouse strain C57BL6J/rd le gus-s ${ }^{\mathrm{h}}$ which shows retinal degeneration $(r d)$ and is characterised by the loss of photoreceptors, ${ }^{21,22}$ and the Swiss Webster (SW) mouse strain, formerly associated with congenital cataract. ${ }^{23,24}$ A semiquantitative RT-PCR experiment measuring opsin expression present in the outer segments and the outer nuclear layer of the photoreceptors ${ }^{25}$ was performed in the mutant mouse strains and a healthy control animal. Consistent with the complete loss of photoreceptors in both mutant mice strains, no opsin expression could be detected in the retinal tissues obtained from the homozygous $r d$ mouse as well as the SW mouse (Figure 4, row 2). In contrast, apparent normal expression of the murine Cacna1f gene could be demonstrated in the SW mouse, and, at a reduced level, in the $r d$ mouse. Overall, the expression pattern of CACNA1F/Cacna1f appears to be identical to the tyrosine kinase Jak1 (Figure 4, row 1 and 3 respectively). This gene is known to be expressed in the inner parts of the nuclear layer and the retinal ganglion cell layer, ${ }^{26}$ with the Jak1 protein being part of known signal transduction pathways. ${ }^{26}$

\section{Discussion}

Genotype-phenotype correlation between CACNA1F mutations and CSNB2

Thirty-three families or patients participating in this study were diagnosed as suffering from the incomplete CSNB phenotype after ophthalmological examinations at the University Eye Hospitals in Tübingen, Regensburg, Paris and Basel. One family was referred from Belgium. In brief, all patients displaying an essentially normal fundus were tested for the presence of a Schubert-Bornschein type ERG that is characterised by a normal a-wave with an extremely reduced b-wave in the maximal response of the ISCEV standard protocol. Such a 'negative ERG' together with impaired cone function, as can be seen in scotopic $30 \mathrm{Hertz}$ flicker responses and dark adaptation tests, was noted in all patients and allowed discrimination between CSNB1 and CSNB2 families.

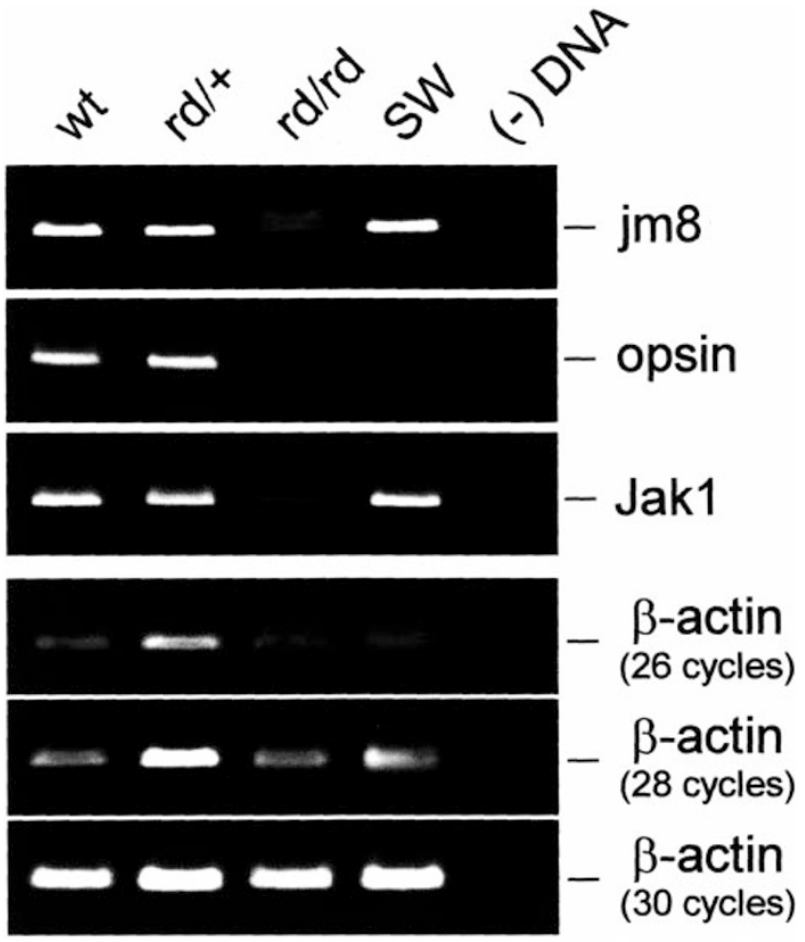

Figure 4 Semi-quantitative RT - PCR expression studies in mouse strains (wt: wild type, $r d /+, r d / r d$, and SW). Note that the expression profile of Cacnalf (here jm8) is identical to that of Jak1 (panels 1 and 3 respectively) and thus suggests expression of Cacna $1 f$ in retinal cell types other than the photoreceptors. The housekeeping gene $\beta$-actin was used as a reference template employing different numbers of PCR cycles to monitor retrotranscription fidelity and to trigger for amplification efficiencies (panels 4-6).

We identified disease-associated mutations in the CACNA1F gene in 31 out of the 34 unrelated patients with the incomplete type of XLCSNB. Additionally, one family and a single sporadic case diagnosed previously as ÅIEDrelated were also shown to carry mutations in this gene. It is interesting to note that reevaluation of the literature indicated full compatibility of the patients' ophthalmological phenotypes with CSNB2. Family F40, showing a frameshift mutation in the CACNA1F gene (Figure 3, Table 1) has previously been diagnosed, due to the observation of a slightly reduced a-wave, with an ÅIED-related phenotype. ${ }^{18}$ Other clinical data, however, were more compatible with features known from CSNB2. Specifically, the $b$-wave in the mixed response for the white stimulus was greatly suppressed rather than being normal as observed in ÅIED. ${ }^{13}$ Similarly, mainly due to a hypopigmented fundus, a sporadic patient (S41, Table 1) that had previously been suspected to display an ÅIED-related phenotype, was more suggestive of CSNB2.

Intriguing is the spectrum of alterations found in family T9. As genes like rhodopsin and PDEB are both associated 
with retinitis pigmentosa and can both cause congenital stationary night blindness, ${ }^{27,28}$ we decided to screen the $R P G R$ gene $^{15}$ for mutations in XLCSNB families that showed no recombination with the $R P 3$ locus. Only in the T9 family could we detect a variant (V36F, Figure 1) that could not be found in 600 control samples tested, and therefore was thought to cause the allelic disease CSNB. ${ }^{16}$ However, subsequent screening of the CACNAF gene in this family revealed first the predicted missense alteration R1171P, not found in 120 control samples tested, and later, the novel disease-causing stop mutation R1816X. What makes these alterations so interesting, is that the ophthalmological phenotype of the affected males from this family display no clinical features of retinitis pigmentosa. Furthermore, these patients do not exhibit a more severe course of incomplete CSNB than males with single mutations in the CACNA1F gene. Thus we conclude, that the two missense mutations, one in RPGR and the other in CACNA1F, are rare polymorphisms instead of mutations afflicting protein function.

Careful analysis of the ERG and dark adaptation data published for two patients of the classic AIED family ${ }^{13}$ shows that all features of incomplete XLCSNB are present, ie attenuated rod b-waves, and a 'negative' ERG waveform to bright flashes (a large a-wave followed by a small bwave), absent photopic flicker potentials, and a moderately elevated dark adaptation with the final threshold being at least 1 log unit higher than normal. The associated hypopigmentation of the fundus might be explained by the high myopia and/or the blond phenotype. Therefore, we speculate that the still lacking mutation in this family may be located intronically or may reside in the promotor region. The same assumption can be made for the three unequivocally CSNB2 typed patients for whom the mutations have yet to be revealed.

\section{Comparison of CACNA1F mutation spectra}

Family F40 is a Finnish family and S41 is a sporadic patient from Switzerland. The family B27 from Belgium shows the novel mutation F742C which segregates within the family. In addition, family B15 exhibiting a novel acceptor splice site mutation, has been sent from Paris. In 29 out of 32 German CSNB2 patients, 27 distinct mutations, 24 of them unique, were identified. These include nine stop or frameshift mutations that cause truncated $\alpha 1$-subunits. In addition, although the deleterious character of the five different splice site mutations could not be demonstrated in the CSNB2 patients, all of them are predicted to cause aberrantly spliced RNAs and truncated proteins. Twelve mutations were of the missense type, with only P1489R occurring twice, and one mutation causes an in-frame deletion of four amino acids. All of the affected amino acids, except for L849P, are highly conserved between the four known $\alpha 1$-subunits of L-type calcium channels.
Of the 30 distinct mutations identified in our study cohort, 20 are described for the first time. Two stop mutations (R82X and R1288X) have also been identified in other populations ${ }^{11}$ and might be caused by the frequent C-to-T transition ${ }^{29}$ rather than by a founder mutation. From eight mutations published recently, ${ }^{9}$ the mutation 3133insC has been found in Mennonite families which have been emigrated since 1683 from Germany, Netherlands, Poland and Russia to North America. ${ }^{11,30}$

No overlap is found between our mutation spectrum and the mutation pattern in five Japanese families carrying the incomplete type of CSNB. ${ }^{12}$ In this study, one missense, one nonsense, one splice site mutation, a single nucleotide insertion and a del/ins combination could be detected. The latter has also been identified by Boycott et al. ${ }^{11}$ as families from Japan had been included in this study.

\section{Congenital stationary night blindness and channelopathies}

L-type calcium channels localised in photoreceptors of nonmammalian vertebrates have been shown to be involved in the regulation of glutamate release which increases during dark adaptation and decreases after hyperpolarisation. ${ }^{31} \mathrm{~A}$ reduced release of glutamate, caused by a diminished influx of calcium ions, might change the sensitivity of dark adaptation. The rod signalling is further transmitted to the bipolar cells, which also have been shown to express L-type calcium channels and thus participate in the regulation of glutamate release. ${ }^{32}$ The glutamate subsequently binds to glutamate receptors of rod amacrine cells, which in turn stimulate the bipolar cells in a feedback loop. Our in situ hybridisation and expression studies using photoreceptorless mouse strains provide further evidence that the CACNA1F/Cacna1f gene is not exclusively expressed in photoreceptors but in other retinal cell types as well. These data are in agreement with the findings of others. ${ }^{10,33-35}$ Moreover, the expression pattern overlaps that of the Jak1 transcript, which has been shown to be expressed in the inner part of the inner nuclear layer and the retinal ganglion cell layer by means of in situ hybridisation and immuno-histochemistry. ${ }^{26}$

\section{Materials and methods Patients and families}

XLCSNB patients were referred by the ophthalmological departments at the Universities in Tübingen (T, H), Regensburg (R), Paris (B) and Basel (S) because of reduced visual acuity, nystagmus and strabismus, with only a minority of patients complaining of poor night vision. Every patient had a general ophthalmologic examination, including best-corrected visual acuity at distance, orthoptic evaluation, slit-lamp biomicroscopy, funduscopy, and Ganzfeld ERG according to the ISCEV standard. Additionally, Gold- 
mann perimetry, dark-adapted whole-field ERG, and lightadapted ERG was performed. Most patients were also tested using color vision evaluation, kinetic or static perimetry, and dark adaptometry as described. ${ }^{5,6,9}$

All family members had normal peripheral visual fields. Visual acuities ranged from 20/30 to 20/400, with elevation of rod dark adaption final thresholds from 0.3 to about 2.5 log units. Dark-adapted whole-field ERGs showed attenuated rod b-waves, and a 'negative' ERG waveform to bright flashes, ie a large a-wave followed by a small b-wave, the peak of which was below the ERG baseline. In the lightadapted ERG, there was a moderate to marked decrease in cone amplitude and a delay of peak times; 30 Hertz flicker stimuli evoked a characteristic double-peak response in most patients. All affected patients were found to have CSNB of the incomplete type, as previously described in some of the families $5,6,9$ and X-linked inheritance was determined in part by pedigree analysis, with affected males occurring in two or more generations with transmitting asymptomatic females.

All investigations followed the tenets of the Declaration of Helsinki, and informed consent and full institutional review board approval were obtained.

\section{Genomic PCR amplifications and SSCP analysis}

Genomic DNA was isolated from peripheral EDTA blood by standard techniques. CACNA1F exons were amplified with intronic primers (published with our permission in Boycott et al. ${ }^{11}$ ). Amplified fragments from 48 exons (Acc. nos. AF235097 and XM_010200) were analysed by SSCP using Hydrolink gels (AT Biochem.) at $20^{\circ} \mathrm{C}$ with and without glycerol as described. ${ }^{15}$ Staining and detection was performed with VistraGreen ${ }^{\mathrm{TM}}$ and the FluorImager (Molecular Dynamics), respectively. Variant bands were reamplified and used for direct sequencing with both the sense and antisense primer using cycle sequencing on automated DNA sequencers (Applied Biosystems).

\section{In situ hybridisation on tissue sections and RT - PCR experiments}

These experiments were essentially carried out as described by Strom and coworkers. ${ }^{9}$ Instead of using a human CACNA1F probe (jm8), we designed the corresponding mouse probe by sequencing cosmids isolated with the jm8 probe from a human cosmid library (RZPD Berlin). Primers used for the amplification of jm8Mus were 5'GGG TTT TCA TGT TCA CTA TCC CG-3' (jm8Mus-c44F1) and 5'-CAT CTC CCA GGT CCT CTT CAT CA-3' (jm8Mus-c48R1; $\mathrm{T}_{\mathrm{A}}$ of $\left.60^{\circ} \mathrm{C}\right)$.

The reverse transcribed (RT-PCR) reactions were performed in a volume of $25 \mu \mathrm{l}$, adding $1-5 \mathrm{mM} \mathrm{MgCl}_{2}$. Each reaction contained $1 \mu \mathrm{l}$ of first strand cDNA (total RNA from mouse eye) as template and 15 pmol each primer. PCR conditions were the following: $94^{\circ} \mathrm{C}$ for $5 \mathrm{~min}, 94^{\circ} \mathrm{C}$ for $30 \mathrm{~s}$, specific $\mathrm{T}_{\mathrm{A}}$ of each primer pair for
$30 \mathrm{~s}, 30 \mathrm{~s}$ at $72^{\circ} \mathrm{C}$, and a final extension at $72^{\circ} \mathrm{C}$ for 5 min. Each PCR was performed for 30 cycles. For the $\beta$ actin control expression, the reaction products were harvested at 26,28 and 30 cycles to perform a semi-quantitative analysis of the amount of first strand cDNAs present in the various samples analysed. The oligonucleotides used were designated XAHR20 (5'-ACC CAC ACT GTG CCC ATC TA-3') and XAHR17 5'-CGG AAC CGC TCA TTG CC-3') (TA of $58^{\circ} \mathrm{C}$; Acc. no.: X03765). For testing opsin expression we applied the primer pair opsinF (5'-TTC ACC ACC ACC CTC TAC AC-3') and opsinR (5'-GTT GAG GGT GGT CTT GGT GG-3') at a $T_{A}$ of $58^{\circ} \mathrm{C}$ (Acc. no.: M55171). Finally, simultaneous expression of the protein kinase acting in signal transduction pathways was accomplished with oligonucleotides Jak1F (5'-ATG TCC ACC CAA CTG TCC TG-3') and Jak1R (5'-AAG GGA GAG TGT CAG CCA AG-3') at an annealing temperature of $58^{\circ} \mathrm{C}$ (Acc. no.: S63728).

\section{Acknowledgements}

We thank the families who participated in this study and Dr Lionel van Maldergem for providing us with DNA samples. We are grateful to Michael Dufault for critical reading of the manuscript. This work was supported by a grant from the Federal Ministry of Education, Science, Research and Technology (Fö. 01KS9602, 01KW9974) the Interdisciplinary Center of Clinical Research (IZKF) Tübingen and the Deutsche Forschungsgemeinschaft by DFG grants Lo457/3-1-3, We1259/11-1 and SFB1785-TP13.

\section{References}

1 Héon E, Musarella MA: Congenital stationary night blindness: a critical review for molecular approaches; In Wright AF, Jay B (eds): Molecular Genetics of inherited Eye Disorders. Switzerland: Harwood Academic, Chur, 1994, pp 277-301.

2 Khouri G, Mets MB, Smith VC, Wendell M, Pass AS: X-linked congenital stationary night blindness: review and report of a family with hyperopia. Arch Ophthalmol 1988; 106: 1417-1422.

3 Miyake Y, Yagasaki K, Horiguchi M, Kawase Y, Kanda T: Congenital stationary night blindness with negative electroretinogram. A new classification. Arch Ophthalmol 1986; 104: 1013-1040.

4 Miyake Y, Horiguchi M, Ota I, Shiroyama N: Characteristic ERG flicker anomaly in incomplete congenital stationary night blindness. Invest Ophthalmol Vis Sci 1987; 28: 1816-1823.

5 Ruether K, Apfelstedt-Sylla E, Zrenner E: Clinical findings in patients with congenital stationary night blindness of the Schubert-Bornschein type. Ger J Ophthalmol 1993; 2: 429-435.

6 Lorenz B, Andrassi M, Miliczek KD: Die inkomplette kongenitale statinäre Nachtblindheit (CSNB). Eine wichtige Differentialdiagnose des kongenitalen Nystagmus. Klin Monatsbl Augenheilkd 1996; 208: 48-55.

7 Bech-Hansen NT, Naylor MJ, Maybaum TA et al: Mutations in $N Y X$, encoding the leucine-rich proteoglycan nyctalopin, cause $\mathrm{X}$-linked complete congenital stationary night blindness. Nature Genet 2000; 26: 319-323.

8 Pusch CM, Zeitz C, Brandau O et al: The complete form of Xlinked congenital stationary night blindness is caused by mutations in a gene encoding a leucine-rich repeat protein. Nature Genet 2000; 26: 324-327.

9 Strom TM, Nyakatura G, Apfelstedt-Sylla E et al: An L-type calcium channel gene mutated in incomplete X-linked congenital stationary night blindness. Nature Genet 1998; 19: 260-263. 
10 Bech-Hansen NT, Naylor MJ, Maybaum TA et al: Loss-of-function mutations in a calcium-channel alpha 1-subunit gene in Xp11.23 cause incomplete X-linked congenital stationary night blindness. Nature Genet 1998; 19: 264-267.

11 Boycott KM, Maybaum TA, Naylor MJ et al: A summary of 20 CACNA1F mutations identified in 36 families with incomplete $\mathrm{X}$-linked congenital stationary night blindness, and characterisation of splice variants. Hum Genet 2001; 108: 91-97.

12 Nakamura M, Ito S, Terasaki H, Miyake Y: Novel CACNA1F mutations in Japaniese patients with incomplete congenital stationary nightblindnes. Invest Ophthalmol Vis Sci 2001; 42: 1610-1616.

13 Elenius V, Eriksson A, Forsius H: ERG in a case of X-chromosomal pigment deficiency of fundus in inombination wiht mypoia, dyschromatopsia and defective dark-adaptation. The Clinical Value of Electroretinography, ISCERG Symp. Ghent 1966, pp 369 -377. Karger, Basel/New York 1968.

14 Alitalo T, Kruse TA, Forsius H, Eriksson AW, de la Chapelle A: Localization of the Aland Island eye disease locus to the pericentromeric region of the $\mathrm{X}$ chromosome by linkage analysis. $\mathrm{Am} \mathrm{J}$ Hum Genet 1991; 48: 31-38.

15 Meindl A, Dry K, Herrmann K et al: A gene (RPGR) with homology to the RCC1 guanine nucleotide exchange factor is mutated in Xlinked retinitis pigmentosa (RP3). Nature Genet 1996; 13: 35-42.

16 Herrmann K, Meindl A, Apfelstedt-Sylla E et al: RPGR mutation analysis in patients with retinitis pigmentosa and congenital stationar night blindness. Am J Hum Genet 1996; 59 (Suppl.): A263.

17 Babitch J: Channel hands. Nature 1990; 346: 321-322.

18 Carlson S, Vesti E, Raitta C, Donner M, Eriksson AW, Forsius H: Clinical and electroretinographic comparison between Aland Island eye disease and a newly found related disease with X-chromosomal inheritance. Acta Ophthalmologica 1991; 69: 703 - 710 .

19 Glass IA, Good P, Coleman MP et al: Genetic mapping of a cone and rod dysfunction (Aland Island eye disease) to the proximal short arm of the human X chromosome. J Med Genet 1993; 30: 1044-1050.

20 Weleber RG, Pillers AM, Powell BR, Hanna CE, Magenis E, Buist NRM: Aland Island eye disease (Forsius-Eriksson Syndrome) associated with contiguous deletion syndrome at Xp21 similarity to incomplete congenital stationary night blindness. Arch Ophthalmol 1989; 107: 1170-1179.

21 Lem J, Flannery JG, Li T, Applebury ML, Faber DB, Simon MI: Retinal degeneration is rescued in transgenic $r d$ mice by expression of the cGMP phosphodiesterase $B$ subunit. Proc Natl Acad Sci USA 1992; 89: $4422-4426$.
22 Pittler SJ, Keeler E, Sidman RL, Baehr W: PCR analysis of DNA from 70-year-old sections of rodless retina demonstrates identity with the mouse $r d$ defect. Proc Natl Acad Sci USA 1993; 90: 96169619.

23 Tissot RG, Cohen C: A new congenital cataract in the mouse. $J$ Hered 1972; 63: 197-201.

24 Tripathi BJ, Tripathi RC, Borisuth NSC, Dhalival R, Dhalival D: Rodent models of congenital and hereditary cataract in man. Lens and Eye Toxicity Research 1991; 8: 373 - 413.

25 Brann MR, Young WS: Localization and quantitation of opsin and transducin mRNAs in bovine retina by in situ hybridization histochemistry. FEBS Letters 1986; 200: 275 - 278.

26 Yang X, Chung D, Cepko CL: Molecular cloning of the murine JAK1 protein tyrosine kinase and its expression in the mouse central nervous system. J Neuroscience 1999; 13: 3006-3017.

27 Sieving PA, Fowler ML, Bush RA et al: Constitutive 'light' adaptation in rods from G90D rhodopsin: a mechanism for human congenital night blindness without rod cell loss. J Neuroscience 2001; 15: 5449-5460.

28 Gal A, Orth U, Baehr W, Schwinger E, Rosenberg T: Heterozygous missense in the rod cGMP phosphodiesterase beta-subunit gene in autosomal dominant stationary night blindness. Nature Genet 1994; 7: 64-68.

29 Lindahl T: Instability and decay of the primary structure of DNA. Nature 1993; 362: 709-715.

30 Boycott KM, Pearce WG, Bech-Hansen NT: Clinical variability among patients with incomplete X-linked congenital stationary night blindness and a founder mutation in CACNA1F. Can J Ophthalmol 2000; 35: 204-213.

31 Schmitz Y, Witkovsky P: Dependence of photoreceptor glutamate release on a dihydropyridin-sensitive calcium channel. Neuroscience 1997; 78: 1209-1216.

32 von Gersdorff H, Sakaba T, Berglund K, Tachibana M: Submillisecond kinetics of glutamate release from a sensory synapse. Neuron 1998; 21: $1177-1188$.

33 Naylor MJ, Rancourt DE, Bech-Hansen NT: Isolation and characterization of a calcium channel gene, Cacna1f, the murine orthologue of the gene for incomplete X-linked congenital statoinary night blindess. Genomics 2000; 66: 324-327.

34 Morgans CW: Localization of the $\alpha_{1 \mathrm{~F}}$ calcium channel subunit in the rat retina. Invest. Ophthalmol Vis Sci 2001; 42: 2414-2418.

35 Morgans CW, Gaughwin P, Maleszka R: Expression of the $\alpha_{1}$ calcium channel subunit by photoreceptors in the rat retina. Mol Vis 2001; 7: 202-209. 